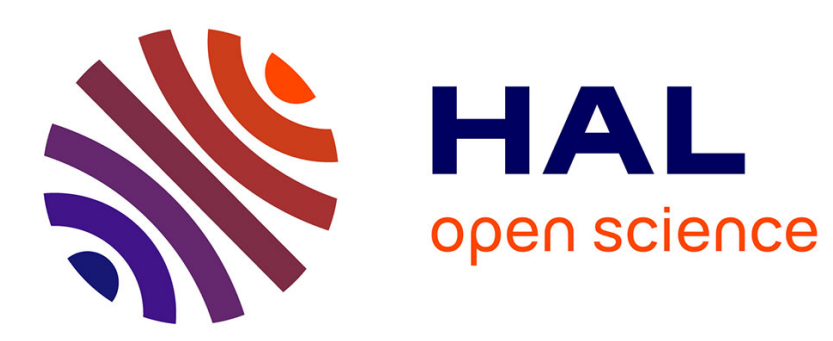

\title{
Can an herbivore affect where a top predator kills its prey by modifying woody vegetation structure?
}

Nicolas Ferry, Moreangels Mbizah, Andrew Loveridge, David Macdonald, Stéphane Dray, Hervé Fritz, Marion Valeix

\section{- To cite this version:}

Nicolas Ferry, Moreangels Mbizah, Andrew Loveridge, David Macdonald, Stéphane Dray, et al.. Can an herbivore affect where a top predator kills its prey by modifying woody vegetation structure? Oecologia, 2020, 192 (3), pp.779-789. 10.1007/s00442-020-04617-9 . hal-03013353

\section{HAL Id: hal-03013353 https://hal.science/hal-03013353}

Submitted on 19 Nov 2020

HAL is a multi-disciplinary open access archive for the deposit and dissemination of scientific research documents, whether they are published or not. The documents may come from teaching and research institutions in France or abroad, or from public or private research centers.
L'archive ouverte pluridisciplinaire HAL, est destinée au dépôt et à la diffusion de documents scientifiques de niveau recherche, publiés ou non, émanant des établissements d'enseignement et de recherche français ou étrangers, des laboratoires publics ou privés. 

vegetation structure?

4 Nicolas Ferry $^{1 * \#}$, Moreangels M. Mbizah ${ }^{2 *}$, Andrew J. Loveridge ${ }^{2}$, David W.

5 Macdonald $^{2}$, Stéphane Dray ${ }^{1}$, Hervé Fritz ${ }^{1,3,4}$, Marion Valeix ${ }^{1,2,3}$.

$6 \quad{ }^{1}$ CNRS, Université de Lyon, Université Lyon 1, Laboratoire de Biométrie et Biologie Evolutive

$7 \quad$ UMR 5558, F-69622 Villeurbanne, France.

$8{ }^{2}$ Wildlife Conservation Research Unit, Recanati-Kaplan Centre, Department of Zoology, Oxford

9 University, Tubney House, Abingdon Road, Oxford OX13 5QL, UK.

$10{ }^{3}$ LTSER France, Zone Atelier "Hwange”, Hwange National Park, Bag 62, Dete, Zimbabwe -

11 CNRS HERD (Hwange Environmental Research Development) program.

$12{ }^{4}$ Sustainability Research Unit, Nelson Mandela Metropolitan University, George Campus,

13 Madiba Drive, 6531 George, South Africa.

$14 *$ Both authors contributed equally to this work.

15 \# Author to whom correspondence should be sent: e-mail: ferrynicolas@me.com

The first and second author contributed equally to this paper. NF carried out the statistical analyses and drafted the manuscript. MM collected field data and drafted the manuscript. MV conceived and designed the study, coordinated the study, and critically revised the manuscript. AJL designed the study, coordinated field data collection and critically revised the manuscript. SD helped with the statistical analyses, the interpretation of the results and revised the manuscript. HF and DWM helped coordinate the study, interpret the results and revised the manuscript. 


\section{Abstract}

17 In large mammal communities, little is known about modification of interspecific

18 interactions through habitat structure changes. We assessed the effects of African

19 elephants (Loxodonta africana) on features of woody habitat structure that can affect

20 predator-prey interactions. We then explored how this can influence where African lions

21 (Panthera leo) kill their prey. Indeed, lions are stalk-and-ambush predators and habitat

22 structure and concealment opportunities are assumed to influence their hunting success.

23 During two years, in Hwange National Park, Zimbabwe, kill sites ( $\mathrm{n}=167)$ of GPS-

24 collared lions were characterized (visibility distance for large mammals, distance to a

25 potential ambush site and presence of elephant impacts). We compared characteristics of

26 lion kill sites with characteristics of random sites (i) at a large scale (i.e, in areas

27 intensively used by lions, $\mathrm{n}=418$ ) and (ii) at the microhabitat scale (i.e., in the direct

28 surrounding available habitat, $<150 \mathrm{~m}, \mathrm{n}=167)$. Elephant-impacted sites had a slightly

29 higher visibility and a longer distance to a potential ambush site than non-impacted sites,

30 but these relationships were characterized by a high variability. At large scale, kill sites

31 were characterized by higher levels of elephant impacts compared to random sites. At

32 microhabitat scale, compared to the direct nearby available habitat kill sites were

33 characterized by a reduced distance to a potential ambush site. We suggest a conceptual

34 framework whereby the relative importance of habitat features and prey abundance could

35 change upon the scale considered.

36 Key words: ecosystem engineer, indirect effects, apex predator, megaherbivores,

37 predator-prey relationships. 


\section{Introduction}

39 Species within an ecosystem are linked by a network of interspecific interactions (e.g.

40 predation, competition, facilitation), which ultimately drives ecosystem functioning

41 (Wardle et al. 2004). There is an increasing awareness that these interactions are dynamic

42 and can be mediated by abiotic (e.g. climate change - Tylianakis et al. 2008, van der

43 Putten et al. 2010) and biotic factors (e.g. parasitism - Hatcher et al. 2006, non-lethal

44 effects of predators that mediate interspecific prey competition - Preisser \& Bolnick

45 2008). In these cases, the interaction between two species can be modified by a third

46 species (hereafter "interaction modification", Wootton 1993). This process can arise from

47 a change of a plastic trait of one of the two main species interacting (i.e. trait-mediated

48 interaction modification) or through alteration of the environment in which the

49 interaction takes place (i.e. environment-mediated interaction modification, Wootton

50 1993, 2002, Dambacher \& Ramos-Jiliberto 2007).

51 Questions have arisen about how habitat changes (diversity and/or physical

52 structure) may affect interspecific interactions (Petren \& Case 1998). In the current

53 context of biodiversity loss, many studies have focused on anthropogenic alterations of

54 the habitat (e.g. Tylianakis et al. 2007), but other ecosystem engineer species (Jones et al.

55 1994) can affect habitats (Crooks 2002), and ultimately interspecific interactions

56 (Marquis \& Lill 2007). Arditi et al. (2005) even designated ecosystem engineer species as

57 "interaction modifiers" due to their capacity to modulate their environment. Interaction

58 modifications were shown to drive community dynamics in systems with few species

59 (Werner \& Peacor 2003, Preisser et al. 2007, Abrams 2010). There is now growing

60 impetus from other recent works to address the challenges of detecting, measuring and 
61 testing the potential role of interaction modifications in complex systems such as natural

62 communities (e.g. Wootton 1994, Peacor \& Werner 2001, Okuyama \& Bolker 2007).

63 Such an understanding is key to improve our ability to forecast how ecosystems will

64 respond to global changes (Kéfi et al. 2012) as interaction modifications are often

65 identified as the cause of unexpected responses to perturbation (Terry et al. 2017 and

66 references therein).

67 The African elephant (Loxodonta africana) is an ecosystem engineer (Bond 1994).

68 While the effects of elephants on vegetation structure through their foraging activity start

69 to be well understood (review in Guldemond \& van Aarde 2008), the consequences of

70 elephant-induced vegetation changes on the whole ecosystem remain unknown as a

71 diversity of indirect effects is documented (Pringle 2008, Valeix et al. 2011, Coverdale et

72 al. 2016). In particular, little is known about the environment-mediated modifications of

73 predator-prey relationships by elephants. Yet, elephants affect the vegetation structure,

74 especially in the understory (Coverdale et al. 2016, Ferry 2018). Further, predation is

75 mediated by physical features of habitats (Bell 1991, Kauffman et al. 2007) and has

76 cascading effects down the food chain (Estes et al. 2011). To our knowledge, two studies

77 highlighted elephant-induced modification of predator-prey relationships. Tambling et al.

78 (2013) showed that elephants, by fragmenting very dense vegetation, improve access for

79 lions, which may ultimately lead to an increased predation by lions on the small prey

80 hiding in this very dense vegetation. Fležar et al. (2019) simulated elephant-induced

81 habitat change at two spatial scales: (i) at the "patch" scale, by comparing high-quality

82 grassland sites with high visibility against ones with low visibility (due to dense woody

83 vegetation) and (ii) at the "within-patch" scale by adding coarse woody debris, potential 
84 escape impediment for prey, in open areas. They then assessed the perceived predation

85 risk by different herbivores. They revealed different responses of prey at the two scales

86 and argue that depending on the scale, elephants' impact on the risk landscape could be

87 both to hamper kill success (by opening up vegetation, improving visibility and lowering

88 ambush opportunity) as well as facilitate kill success (by dropping woody debris that may

89 lower visibility and create escape impediments). Elephants are thus able to modify

90 predator-prey interactions by altering habitats and different manifestations of elephant-

91 induced changes on the vegetation (e.g., visibility and coarse woody debris) could act at

92 different spatial scales.

93 Here, we investigated whether elephants, through their impacts on vegetation

94 structure (that lead to changes in visibility distance for large mammals and changes in the

95 distance to a potential ambush site), can influence predator-prey interactions between

96 African lions (Panthera leo) and their prey in a woody savanna ecosystem. Lions are

97 stalk-and-ambush predators that rely on features of the habitat providing concealment

98 (typically dense vegetation) to approach and attack their prey (Hopcraft et al. 2005,

99 Loarie et al. 2013, Davies et al. 2016). Therefore, habitat characteristics are expected to

100 play an important role in selecting areas that may increase hunting success (the ambush-

101 habitat hypothesis - Hopcraft et al. 2005). This has been illustrated in Kruger National

102 Park, South Africa, where lions kill their prey within nine meters of a potential ambush

103 site (Loarie et al. 2013). Elephants are thus likely to affect where lions hunt and/or

104 successfully hunt (i.e. kill) their prey.

105 The aim of this study is two-fold: (1) to assess whether elephant impacts on

106 woody vegetation are associated with an increased visibility and a change in the distance 
107 to a potential ambush site, and (2) to test the hypothesis that lions kill less in areas

108 impacted by elephants (as we expect them to be more successful hunters in areas with

109 denser vegetation thus greater opportunities for concealment). This second aim was

110 investigated at two different scales: (i) we first compared lion kill sites with random sites

111 in areas intensively used by lions to assess if among all habitats used by lions, kill sites

112 were characterized by denser vegetation and less elephant impacts (the "large" scale

113 hereafter), and (ii) we then compared the characteristics of lion kill sites with

114 characteristics of the direct surrounding available habitat $(<150 \mathrm{~m})$ to assess if lions

115 killed more in closed microhabitats that were less impacted by elephants (the

116 "microhabitat" scale hereafter). Together, the results will allow an assessment of the

117 extent to which elephants can induce environment-mediated trophic interaction

118 modification between lions and their prey in woodland savannas and if this modification

119 is scale-dependent.

\section{Materials and methods}

122 Study site - Hwange National Park covers $\sim 15000 \mathrm{~km}^{2}$ of semi-arid dystrophic (low

123 nutrient soil) savanna in western Zimbabwe (1900’ $\left.\mathrm{S}, 26^{\circ} 30^{\prime} \mathrm{E}\right)$. The vegetation is

124 primarily woodland and bushland savanna. The east and southern parts of the park are

125 dominated by open wooded savannas on Kalahari sands, primarily teak woodland

126 (Baikiaea plurijuga) and Combretum/Terminalia woodlands. Batoka basalt and Karoo

127 sediments in the north and north-west of the park are dominated by Colophospermum

128 mopane woodlands interspersed with grassland vleis. The long-term mean annual rainfall

129 is $~ 600 \mathrm{~mm}$, which falls primarily between October and April. The surface water 
130 available to animals is found in natural as well as artificial waterholes. The study area is

131 located in the northern region of Hwange National Park $\left(\sim 7000 \mathrm{~km}^{2}\right)$ where lion density

132 is estimated around 4.3 individuals $/ 100 \mathrm{~km}^{2}$ (Loveridge et al. 2016), and elephant density

133 is estimated above 2 individuals $/ \mathrm{km}^{2}$ (Chamaillé-Jammes et al. 2008).

134 Data - We collected data between 2014 and 2015 from 12 female and 15 male lions from

135 different coalitions and prides equipped with 2D size AWT GPS radio-collars. The lions'

136 locations were available hourly and for some lions every two hours, day and night.

137 Potential lion kills were attained by identifying clusters of coordinates that had more than

1384 hours of sequential locations within a defined proximity $(150 \mathrm{~m}$, see also Tambling et

139 al. 2010). In the field, these clusters were searched for a carcass or the remains of a

140 carcass and classified as kill sites based on the evidence of a kill. We confirmed lion kills

141 when the presence of a carcass was associated with indications of a hunt / struggle from

142 animal tracks (observed by skilled field trackers) and / or broken and tramped vegetation

143 and / or from the condition of any remaining hide bearing claw and bite marks typical of

144 lion predation. Carcasses found were classified to species based on the body size of the

145 animal killed and the presence of identifiable material, such as horns, jaws, bones, and

146 hair. We made the assumption that the kill site is a good proxy of the environment within

147 which the lion decided to start the hunt, as lion is a stalk-and-ambush predator attacking

148 and killing prey at short distances (van Orsdol 1984, Haas et al. 2005). This assumption

149 has been made in several previous works (Davidson et al. 2012, 2013, Loarie et al. 2013,

150 Davies et al. 2016). In total, 705 clusters were monitored among which 167 were

151 identified as kill sites and 538 were not (called "non-kill sites" hereafter). For the 167 kill

152 sites and for 251 non-kill sites, we identified a paired random site (with a random 
153 direction, a random distance between 50 and $150 \mathrm{~m}$ from the kill for kill sites and from

154 the GPS point identified as the start of the cluster for non-kill sites). In total, 418 random

155 sites were characterized and represented habitats intensively used by lions. Among these

156 random sites, 167 were associated to a kill site and represented the direct surrounding

157 available habitat. For each kill site, non-kill site and random site, we measured the

158 distance to a potential ambush site (DPAS hereafter, a potential ambush site was any

159 habitat feature able to conceal a lying lion, i.e. most of the time a dense bush in the study

160 ecosystem) and the visibility. Visibility at each site was assessed by using two $50 \mathrm{~cm} \mathrm{x}$

$16150 \mathrm{~cm}$ white boards. The two boards were set so that one board was at $10-60 \mathrm{~cm}$

162 (representative of the height of a crawling lion) and the other was at 100-150cm

163 (representative of a standing lion). One person stood at the location of the kill or at the

164 centre of the random site, while another person held the boards, walked away from the

165 centre in the four cardinal directions and recorded the distance at which the person at the

166 centre of the site could not see each board anymore. The four distances obtained from the

167 four cardinal directions were then averaged ("visibility" hereafter). As lions are more

168 successful at capturing prey when attacks are launched at short distance $(<7.6 \mathrm{~m}$ for

169 Thomson's gazelle, $15 \mathrm{~m}$ for wildebeest and zebras, Haas et al. 2005), elephant impacts

170 were assessed within a $25 \mathrm{~m}$ radius of the kill for the kill sites, of the random point for the

171 random sites and of the GPS point identified as the start of the non-kill sites. The extent

172 of elephant impact was determined by the definition of five classes of percentage of trees

173 impacted by elephants (broken, coppiced and/or uprooted): class 0: no impact; class 1: [1-

$17425 \%$ ]; class 2: [26\%-50\%]; class 3: [51\%-75\%]; and class 4 : [76\%-100\%]. 
175 Analyses -Proximity to water is commonly thought to influence the level of herbivore

176 impacts on the vegetation (i.e. the "piosphere effect", Lange 1969), but this has recently

177 been debated in wild protected areas (Chamaillé-Jammes et al. 2009). We therefore

178 preliminarily checked the existence of a link between distance to water and the existence

179 of elephant impacts on the vegetation and found that sites (random sites and kill sites)

180 impacted by elephants were not located closer to waterholes than sites not impacted by

181 elephants (Kruskal-Wallis test, $\chi^{2}=5.51, \mathrm{df}=3$, $\mathrm{p}$-value $=0.14$ ).

182 Effect of elephants on woody habitat structure - Visibility at $100-150 \mathrm{~cm}$ was highly

183 correlated to visibility at $10-60 \mathrm{~cm}(\mathrm{r}=0.91, \mathrm{t}=75, \mathrm{df}=1121, \mathrm{p}<0.001)$, so only results

184 on the visibility at $10-60 \mathrm{~cm}$ (visibility hereafter) were considered in the subsequent

185 analyses. We assessed the effect of the level of elephant impacts on (1) the visibility with

186 a simple linear model performed on log-transformed visibility data and on (2) the DPAS

187 with a truncated linear regression as data distribution was left truncated at $0 \mathrm{~m}$ on log-

188 transformed DPAS data ('truncreg' package from open source Software R 3.3.1 R.

189 Development Core Team, 2014). All kill sites, all non-kill sites and all random sites were

190 included in this analysis to best describe the link between the level of elephant impact

191 and the vegetation characteristics.

192 Lion kill site characteristics - For the subsequent analyses, non-kill sites were excluded

193 as they could have represented any lion's activity (e.g., resting site). These sites could

194 have been under selection by lions (e.g., habitat with higher woody cover for shadow

195 preferred) and thus led to a bias in our results/interpretation. At the large scale, we

196 compared the characteristics of lion kill sites with characteristics of the habitats of all the

197 random sites (associated to kill sites and to non-kill sites), representing areas intensively 
198 used by lions. We used logistic regressions to develop resource selection functions (RSF),

199 with the dependent variable being 1 for kill sites and 0 for random sites. We performed a

200 first logistic regression to assess if lions kill more in low visibility environments where

201 prey can be closely approached thanks to low DPAS. For this first logistic regression, the

202 explanatory variables are visibility and DPAS. No strong correlation was observed

203 between these two variables, which were therefore kept for the analyses (Pearson's

204 correlation coefficient visibility-DPAS $=0.38$ ). We performed a second logistic

205 regression to assess if the level of elephant impacts on vegetation structure influences

206 lion kill site location. In this second logistic regression, the explanatory variable was the

207 level of elephant impacts. A model selection was performed using the function "dredge"

208 ('MuMin’ package) using the Bayesian Information Criterion (BIC) for a compromise

209 between the explanatory power and the parsimony of the models and model averaging

210 was performed on all the models (Burnham \& Anderson 2004). Variables considered as

211 important were those for which $\beta \pm 1.96^{*}$ SE did not include zero. At the microhabitat

212 scale, we compared the characteristics of lion kill sites with the characteristics of the

213 direct surrounding available habitat (represented by the random site associated to each

214 kill site). A paired Generalized Estimating Equations (GEE) model was performed using

215 the package "gee" to remove all the variability between the different pairs and focus only

216 of the variability within each pair (Liang \& Zeger 1986). We conducted the same two

217 regression analyses as above. For this analysis, the quasi-likelihood criterion (QIC) was

218 used (Liang \& Zeger 1986) and a model averaging was performed on all the models. As

219 no difference between lion sexes was observed (Online Resource 1), all kill sites

220 identified were used and pooled together independently of whether the kill site was found 
221 using GPS-collar data from a female or a male lion. Further, our data did not allow

222 assessing if the collared individual was the one that made the kill, and male and female

223 lions were regularly observed together (70.1\% of all lions' observations) in Hwange

224 National Park at the time of the study.

\section{$227 \quad$ Results}

228 Kills were not evenly distributed over the different classes of shrub layer cover and over

229 the different prey species (Online Resource 2). The main prey of lions were greater kudu

230 Tragelaphus strepsiceros (27\%), followed by African buffalo Syncerus caffer (20\%) and

231 plains zebra Equus quagga (12\%, Online Resource 2). DPAS and visibility at kills for

232 each prey species are presented in Online Resource 3.

234 Effect of elephants on woody vegetation structure - For each class of level of elephant

235 impacts (0: no impact; 1: [1-25\%]; 2: [26\%-50\%]; 3: [51\%-75\%]; and 4: [76\%-100\%]),

236 the number of study sites (including all kill sites, non-kill sites and random sites) was

237 respectively: $453,275,205,132$, and 55 . The log-visibility increased as the level of

238 elephant impacts increased (estimate $\pm \mathrm{SE}=0.14 \pm 0.015, \mathrm{t}=9.04, \mathrm{p}<0.001$, Table 1a,

239 Fig. 1a), and the log-transformed DPAS also increased as the level of elephant impacts

240 increased (estimate $\pm \mathrm{SE}=0.17 \pm 0.02, \mathrm{t}=7.5, \mathrm{p}<0.001$ ), Table $1 \mathrm{~b}$, Fig. 1b). On

241 average, there was a difference of $14 \mathrm{~m}$ for the visibility (mean Level $0=16.7 \mathrm{~m}$, mean Level 4

$242=30.7 \mathrm{~m}$ ) and $3 \mathrm{~m}$ for the DPAS (mean Level $0=2.4$, mean Level $4=5.4 \mathrm{~m}$ ) between habitats 
243 not impacted by elephants and those with the highest level of elephant impacts. It is

244 noteworthy that there exists a high variability in the visibilities and the DPAS (Fig. 1).

246 Lion kill site characteristics - In the first analyses at large scale, comparing kill sites to

247 the all the random sites, representing available habitat in areas intensively used by lions,

248 we revealed that the level of elephant impacts was the only variable to explain lion kill

249 site characteristics (Table 2a). Lion kills were located in habitats with higher levels of

250 elephant impacts (estimate $\pm \mathrm{SE}=0.27 \pm 0.09$, Fig. 2a, see Online Resource 4 for raw

251 data). At the microhabitat scale, when we compared the characteristics of lion kill sites to

252 the characteristics of the direct surrounding habitat (within-pair comparison approach),

253 we revealed that the DPAS was the only variable to explain lion kill site characteristics

254 (Table 2b). Lion kill sites were preferentially located in habitats characterized by a

255 reduced DPAS compared to the direct nearby available habitat (estimate $\pm \mathrm{SE}=-0.44 \pm$

2560.19 , Fig. 2b). In the kill sites, the mean DPAS value was $5.86 \mathrm{~m}$, whereas it was $7.56 \mathrm{~m}$

257 in the random sites representing a decrease of $1.7 \mathrm{~m} \mathrm{(22 \%} \mathrm{of} \mathrm{the} \mathrm{mean} \mathrm{DPAS} \mathrm{value} \mathrm{of}$

258 random sites).

261 Discussion

262 In this study, we first assessed the effects of elephants on features of woody habitat

263 structure that can be key for the ecology of predator-prey interactions, i.e. visibility and

264 distance to a potential ambush site. Elephant-induced vegetation changes tended to be

265 associated with an increase in visibility (as observed by Valeix et al. 2011). Regarding 
266 distance to a potential ambush site, elephants could either increase it (e.g., by removing

267 large bushes or by reducing the crown diameter of bushes - see Ferry 2018) or reduce it

268 (e.g., by uprooting or breaking trees, which can create ambush sites behind the trunk,

269 branches and foliage on the ground). Overall, in Hwange National Park, elephant-induced

270 vegetation changes tended to be associated with an increase in distance to a potential

271 ambush site. Even though these average differences were not very large, they can make a

272 difference in dense habitats considering the hunting behaviour of lions, which kill their

273 prey close to dense vegetation (e.g. within 9 meters of a potential ambush site - Loarie et

274 al. 2013). Hence, elephants, by altering visibility and distance to potential ambush site,

275 are likely to affect where lions choose to hunt and/or where they hunt successfully in

276 woodland. Following the ambush-habitat hypothesis (Hopcraft et al. 2005), we initially

277 expected lions to kill more in habitats with lower level of elephant impacts and

278 characterized by lower visibility and a shorter distance to potential ambush site, thus

279 more favourable to lion hunting success (Fig. 3A- expected pattern). This assumption can

280 appear to be in opposition with the results from Tambling et al. (2013) and Davies et al.

281 (2016). This can be explained by the fact that, in these studies, habitats not impacted by

282 elephants were actually so dense (average distance to cover $<1 \mathrm{~m}$ ) that lions were not

283 able to move and hunt inside this dense vegetation, which could be therefore used as a

284 refuge by small prey species (e.g., the duiker Sylvicapra grimmia).

285 In this study, we were limited on the inferences we could make because of two main

286 limitations in our data. The first one is that we were not able to identify hunts in which

287 lions failed, which prevented us from assessing whether there were more kills in a habitat

288 because lions hunted more in this habitat or had a higher hunting success there. The 
second limitation is the lack of information about the contextual abundance and

290 distribution of herbivores during the hunt, which could influence the kill site location as

291 expected under the prey-abundance hypothesis. To partly fill these gaps, we suggest a

292 conceptual framework with different scenarios that could explain the patterns observed

293 based on three different parameters: the probability of prey presence, the probability to

294 hunt (depending either on prey presence or on habitat openness), and the probability to

295 kill a prey (i.e. to hunt successfully) (Fig. 3B). Patterns 3,9 and 11 represent our initial

296 hypothesis, without assumption on prey distribution and with the probability to hunt

297 and/or kill being linked to habitat features only (following the ambush-habitat

298 hypothesis, with more hunt/kills in habitats less impacted by elephants, less open).

299 Contrary to our expectations, at the large scale, when we compared the

300 characteristics of lion kill sites to the characteristics of random sites in areas intensively

301 used by lions, kills were more located in woody habitats characterized by higher levels of

302 elephant impacts, but we did not detect a selection for a lower visibility and a shorter

303 distance to a potential ambush site. This result suggests that other factors than habitat

304 structural features drive lion hunting behaviour at this scale, such as the presence and

305 abundance of prey (i.e., the prey-abundance hypothesis, Hopcraft et al. 2005). If this is

306 the case, it assumes that herbivores select habitats impacted by elephants (representing all

307 the even numbered patterns in Fig. 3). This selection pattern may arise from (i) a

308 coincidence with elephants and other herbivores using the same habitats, (ii) a reduced

309 perceived risk of predation in elephant-impacted habitats due to the higher visibility

310 caused by elephants in these habitats for all herbivore species (Underwood 1982, Valeix

311 et al. 2011), and/or (iii) a facilitative effect of elephants that may increase browse 
312 availability at lower heights within reach of smaller browsers by stimulating tree

313 coppicing, a mechanisms known as "browsing lawns" (Rutina et al. 2005, Fornara \& du

314 Toit 2007). Hence, the fact that lion kills were preferentially found in elephant-impacted

315 habitats at the large scale could be explained by a selection for areas where prey are

316 abundant (patterns 6, 8,14 and 16, Fig. 3) and elephants could be considered as

317 interaction modifiers if they influence prey habitat selection. Evidences about the role of

318 elephants in other herbivore woody habitat selection at this scale still need to accumulate

319 (e.g., herbivore distribution data thanks to camera traps placed on contrasted elephant-

320 impacted habitats).

321 At the microhabitat scale (the within-pair comparison between a kill site and its

322 paired random site), results revealed that lion kills were not preferentially located in

323 habitats impacted by elephants anymore. At this scale, lion kill sites were preferentially

324 located in habitats characterized by a shorter distance to a potential ambush site (patterns

3253 , 4, 7-16, Fig. 3), supporting here our hypothesis of the role of prey catchability

326 (ambush-habitat hypothesis). Interestingly, the visibility did not seem to be a factor as

327 important as the distance to a potential ambush site. An explanation could be that,

328 whatever the visibility, the presence of a few large bushes / broken trees as potential

329 ambush sites is sufficient to lead to a higher probability of kill even in woody habitats

330 with a high visibility. Finally, when combining the two different scales, the only patterns

331 to explain the observed pattern (Fig 3A - observed pattern) with both more kills in

332 impacted habitat at the large scale and more kills in closed habitat at the microhabitat

333 scale are Patterns 8,14 and 16 . These patterns share the same processes: prey select

334 elephant-impacted habitats and a higher probability to hunt in habitat with more prey 
335 (prey-abundance hypothesis). However, they differ in terms of probability to hunt or to

336 kill in closed habitats. Pattern 8 needs a higher probability to kill in closed habitats,

337 Pattern 14 needs a higher probability to hunt in closed habitats and Pattern 16 needs both

338 of them, suggesting therefore that lions are influenced by habitat structure during the

339 hunting process at the microhabitat scale (ambush-habitat hypothesis).

340 Therefore, our results suggest that the main driver of kill site location for lions is

341 likely to be prey abundance at a first scale of selection, and prey catchability at the scale

342 of the direct nearby available habitat $(<150 \mathrm{~m})$. As suggested in previous studies, the

343 prey-abundance and the ambush-habitat hypotheses are not exclusive and could interact

344 with one another to explain lion hunting behaviour (Davidson et al. 2012). Therefore, by

345 affecting the woody vegetation structure, elephants could play an important role in the

346 intensity of predator-prey relationships although in complex ways, as they could act on

347 both predators and prey's behaviour, with different mechanisms involved depending on

348 the scale considered (as suggested by Fležar et al. 2019). We encourage future research to

349 confirm that herbivores select woody habitats impacted by elephants because of the

350 elephant's engineering process and not because of simple coincidence or shared

351 resources. Further, a focus on identifying unsuccessful hunts will be needed to

352 disentangle the roles of the probability to hunt and the probability to kill in closed

353 habitats. This would ultimately help to know which process is influenced by the

354 vegetation structure during the lion hunting behaviour in woodland areas. This task is

355 both conceptually and practically a challenging one, although perhaps it can be

356 accomplished through the deployment of GPS-collars with integrated tri-axial

357 accelerometer-magnetometer (see for example Fröhlich et al. 2012, Wilmers et al. 2017). 
359 suggests that elephants have the potential to influence predator-prey interactions in their

360 ecosystem. In a context of rapidly changing elephant populations worldwide (Chase et

361 al., 2016), it is of importance to understand their indirect role on interspecific

362 interactions. Our results reinforce the idea that elephants, through ecosystem engineering,

363 could act on a multitude of broad-scale ecological processes in wooded savannas (Kerley

364 \& Landman 2006). Further, whereas previous studies of ecosystem engineers have

365 highlighted their effects on other species abundance and richness (Jones et al. 1997), our

366 findings demonstrate the importance of their indirect effect on interspecific interactions

367 (see also Arditi et al. 2005, Marquis \& Lill 2007 and references therein). Finally, we

368 highlighted the importance of multi-scale consideration in interspecific interactions and

369 their modification (see also Fležar et al. 2019). We therefore hope these findings will

370 promote studies on interaction modification, with a multi-scale component (Tylianakis \&

371 Morris 2017) in large mammal communities.

\section{Funding}

375 Acknowledgments

376 The Zimbabwe Research Council and the Zimbabwe Parks and Wildlife Management

377 Authority are kindly acknowledged for providing the opportunity to carry out this research.

378 We sincerely thank Lowani Mpofu, Trust Dube and Gladys Kazembe for their great help

379 with the fieldwork. We thank Craig Tambling, Marion Cordonnier and Simon Chamaillé-

380 Jammes and an anonymous reviewer for their helpful comments on earlier versions of this 
manuscript. The Robertson Foundation, the Recanati-Kaplan Foundation, a CV Starr

382 Scholarship and a grant from the French "Ministère de la recherché" through the "Ecole

383 Doctorale E2M2" of "Université Claude Bernard Lyon 1" funded this research. This

384 collaborative work was facilitated by an International Program for Scientific Cooperation

385 (PICS) grant from the CNRS.

\section{$389 \quad$ Literature cited}

390 Abrams PA (2010) Implications of flexible foraging for interspecific interactions: lessons from simple models. - Funct. Ecol. 2 4: 7-17. doi: 10.1111/j.13652435.2009.01621.x

393 Arditi R, Michalski J, Hirzel AH (2005) Rheagogies: modelling non-trophic effects in food webs. Ecol. Complex. 2:249-258. doi: 10.1016/j.ecocom.2005.04.003

395 Bell WJ (1991) Searching behavior: the behavioural ecology of finding resources 396 Chapman \& Hall, New York.

397 Bond WJ (1994) Keystone species. - In Biodiversity and ecosystem function (eds ED 398 Schulze, HA Mooney), pp 237-253. Springer Berlin Heidelberg.

399 Burnham KP, Anderson DR (2004) Multimodel Inference. - Sociol. Methods Res 33: 400 261-304. doi: 10.1177/0049124104268644

401 Chamaillé-Jammes S, Fritz H, Valeix M, Murindagomo F, Clobert J (2008) Resource 402 variability, aggregation and direct density dependence in an open context: the 
local regulation of an African elephant population. - J. Anim. Ecol. 77: 135-144. doi: 10.1111/j.1365-2656.2007.01307.x

Chamaillé-Jammes S. Fritz H, Madzikanda H (2009) Piosphere contribution to landscape heterogeneity: a case study of remote-sensed woody cover in a high elephant density landscape. - Ecography 32: 871-880. doi: 10.1111/j.16000587.2009.05785.x.

409 Chase MJ et al. (2016) Continent-wide survey reveals massive decline in African savannah elephants. - PeerJ 4: e2354. doi: 10.7717/peerj.2354

411 Coverdale TC et al. (2016) Elephants in the understory: opposing direct and indirect effects of consumption and ecosystem engineering by megaherbivores. - Ecology 97: 3219-3230. doi: 10.1002/ecy.1557

Crooks JA (2002) Characterizing ecosystem-level consequences of biological invasions: the role of ecosystem engineers. - Oikos 97: 153-166. doi: 10.1034/j.16000706.2002.970201.x

\section{Dambacher JM, Ramos-Jiliberto R (2007) Understanding and predicting effects of} modified interactions through a qualitative analysis of community structure. - Q. Rev. Biol. 82: 227-250. Doi: 10.1086/519966

424 Davidson Z, Valeix M, Van Kesteren F, Loveridge AJ, Hunt JE, Murindagomo F, 425 Macdonald DW (2013) Seasonal diet and prey preference of the African lion in a 
waterhole-driven semi-arid savanna. PLoS ONE 8: e55182. doi:

428 Davies AB, Tambling CJ, Kerley GI, Asner GP (2016) Effects of Vegetation Structure on the Location of Lion Kill Sites in African Thicket - PLoS ONE 11: e0149098. doi: 10.1371/journal.pone.0149098

431 Estes JA et al. (2011) Trophic Downgrading of Planet Earth. - Science 333: 301-306. doi:10.1126/science. 1205106

433 Ferry N (2018) Processes involved in the functioning of large mammal communities: the 434 role of the African elephant in the ecology of predator-prey relationships. PhD. $435 \quad$ University of Lyon, France.

436 Fležar U et al. (2019) Simulated elephant-induced habitat changes can create dynamic 437 landscapes of fear. Biological Conservation 237: 267-279. doi: 10.1016/j.biocon.2019.07.012

439 Fornara DA, du Toit JTD (2007) Browsing lawns? Responses of Acacia nigrescens to ungulate browsing in an African savanna. - Ecology 88: 200-209. doi: 10.1890/0012-9658(2007)88[200:blroan]2.0.co;2

442 Fröhlich M, Berger A, Kramer-Schadt S, Heckmann I, Martins Q (2012) Complementing 443 GPS Cluster Analysis with Activity Data for Studies of Leopard (Panthera 444 pardus) Diet. S. Afr. J. Wildl. Res. 42: 104-110. doi: 10.3957/056.042.0208 445 Guldemond R, van Aarde R (2008) A Meta-Analysis of the Impact of African Elephants 446 on Savanna Vegetation. - J. Wildl. Manag. 72: 892-899. doi: 10.2193/2007-072 447 Haas SK, Hayssen V, Krausman PR (2005) Panthera leo. Mamm. Species, 1-11. 
448 Hatcher MJ, Dick JT, Dunn AM (2006) How parasites affect interactions between

449 competitors and predators. - Ecol. Lett. 9: 1253-1271. doi: 10.1111/j.1461-

$450 \quad$ 0248.2006.00964.x

451 Hopcraft JGC, Sinclair ARE, C Packer (2005) Planning for success: Serengeti lions seek 452 prey accessibility rather than abundance. J. Animal Ecol. 74: 559-566. doi:

$453 \quad 10.1111 / j .1365-2656.2005 .00955 . x$

454 Jones CG, Lawton JH, Shachak M (1994) Organisms as Ecosystem Engineers. - Oikos 455 69: $373-386$. doi: $10.2307 / 3545850$

456 Jones CG, Lawton JH, Shachak M (1997) Positive and negative effects of organisms as 457 physical ecosystem engineers. - Ecology 78: 1946-1957. doi: 10.1890/0012$458 \quad 9658(1997) 078[1946:$ paneoo $] 2.0 . c o ; 2$

459 Kauffman MJ, Varley N, Smith DW, Stahler DR, MacNulty DR, Boyce MS (2007)

$460 \quad$ Landscape heterogeneity shapes predation in a newly restored predator-prey

$461 \quad$ system. - Ecol. Lett. 10: 690-700. doi:10.1111/j.1461-0248.2007.01059.x

462 Kéfi S et al. (2012) More than a meal... integrating non-feeding interactions into food

463 webs. - Ecol. Lett. 15: 291-300. doi:10.1111/j.1461-0248.2011.01732.x

464 Kerley GI, Landman M (2006) The impacts of elephants on biodiversity in the Eastern

465 Cape Subtropical Thickets: elephant conservation. - South Af. J. of Science, 102: $466 \quad 395-402$.

467 Lange RT (1969) Piosphere-sheep track and dung patterns. J. of Range Management $468 \quad 22,396-400$

469 Liang KY, Zeger SL (1986) Longitudinal data analysis using generalized linear models. $470 \quad$ Biometrika 73: 13-22. doi: 10.1093/biomet/73.1.13 
471 Loarie SR. Tambling CJ, Asner GP (2013) Lion hunting behaviour and vegetation

472 structure in an African savanna. - Animal Behav. 85: 899-906. doi:

$473 \quad$ 10.1016/j.anbehav.2013.01.018

474 Loveridge AJ, Valeix M, Chapron G, Davidson Z, Mtare G, Macdonald DW (2016)

475 Conservation of large predator populations: Demographic and spatial responses of

476 African lions to the intensity of trophy hunting. - Biol. Conserv. 204: 247-254.

$477 \quad$ doi: $10.1016 / j$. biocon.2016.10.024

478 Marquis RJ, Lill JT (2007) Effects of arthropods as physical ecosystem engineers on

479 plant-based trophic interaction webs. - In: Ohgushi, T. et al. (eds), Ecological

$480 \quad$ Communities. Cambridge University Press, pp. 246-274.

481

doi:10.1017/cbo9780511542701.012

482 Okuyama T, Bolker BM (2007) On quantitative measures of indirect interactions. - Ecol.

483 Lett. 10: 264-271. doi:/10.1111/j.1461-0248.2007.01019.x

484 Peacor SD, Werner EE (2001) The contribution of trait-mediated indirect effects to the net effects of a predator. - Proc. Natl. Acad. Sci. USA PNAS 98: 3904-3908. doi: 10.1073/pnas.071061998

Petren K, Case TJ (1998) Habitat structure determines competition intensity and invasion success in gecko lizards. - Proc. Natl. Acad. Sci. USA PNAS 5: 11739-11744. doi: 10.1073/pnas.95.20.11739

490 Preisser EL, Bolnick DI (2008) The Many Faces of Fear: Comparing the Pathways and 491 Impacts of Nonconsumptive Predator Effects on Prey Populations. - PLoS ONE 3: 492 e2465.doi: 10.1371/journal.pone.0002465 
493 Preisser EL, Orrock JL, Schmitz OJ (2007) Predator hunting mode and habitat domain 494 alter nonconsumptive effects in predator-prey interactions. - Ecology 88: 2744495 2751. doi: $10.1890 / 07-0260.1$

496 Pringle RM (2008) Elephants as agents of habitat creation for small vertebrates at the 497 patch scale. - Ecology 89: 26-33. doi: 10.1890/07-0776.1

498 R Development Core Team (2014) R a language and environment for statistical 499 computing. Vienna, Austria: R Foundation for Statistical Computing, $500 \quad$ http://www.r-project.org

501 Rutina LP, Moe SR, Swenson JE (2005) Elephant Loxodonta africana driven woodland 502 conversion to shrubland improves dry-season browse availability for impalas

503 Aepyceros melampus. - Conserv Biol 11: 207-213. doi: 10.2981/09096396(2005)11[207:ELADWC]2.0.CO;2

505 Tambling CJ, Cameron EZ, du Toit JT, Getz WM (2010) Methods for Locating African 506 Lion Kills Using Global Positioning System Movement Data. - J. Wildl. Manag. 74: 549-556. doi:10.2193/2009-010

508 Tambling CJ, Minnie L, Adendorff J, Kerley GI (2013) Elephants facilitate impact of 509 large predators on small ungulate prey species. - Basic Appl Ecol 14: 694-701. $510 \quad$ doi: $10.1016 /$ j.baae.2013.09.010

511 Terry JCD, Morris RJ, Bonsall MB (2017) Trophic interaction modifications: an 512 empirical and theoretical framework. - Ecol. Lett. 20: 1219-1230. doi: $513 \quad$ 10.1111/ele.12824 
514 Tylianakis JM, Tscharntke T, Lewis OT (2007) Habitat modification alters the structure

515 of tropical host-parasitoid food webs. - Nature 445: 202-205. doi:

$516 \quad 10.1038 /$ nature05429

517 Tylianakis JM, Didham RK, Bascompte J, Wardle DA (2008) Global change and species 518 interactions in terrestrial ecosystems. - Ecol. Lett. 11: 1351-1363. doi:

$519 \quad 10.1111 / \mathrm{j} .1461-0248.2008 .01250 . \mathrm{x}$

520 Tylianakis JM, Morris RJ (2017) Ecological networks across environmental gradients.

$521 \quad$ Annu Rev Ecol Evol Syst., 48.

522 Underwood R (1982) Vigilance Behaviour in Grazing African Antelopes. - Behaviour 79:

523 81-107. doi: $10.1163 / 156853982 \times 00193$

524 Valeix M, Fritz H, Sabatier R, Murindagomo F, Cumming D, Duncan P (2011) Elephant-

525 induced structural changes in the vegetation and habitat selection by large

526 herbivores in an African savanna. - Biol. Conserv. 144: 902-912. doi:

$527 \quad 10.1016 /$ j.biocon.2010.10.029

528 Van der Putten WH, Macel M, Visser ME (2010) Predicting species distribution and

529 abundance responses to climate change: why it is essential to include biotic

530 interactions across trophic levels. - Philos. Trans. R. Soc. Lond., B, Biol. Sci.

$531 \quad 365: 2025-2034$. doi: 10.1098/rstb.2010.0037

532 Van Orsdol KG (1984) Foraging behaviour and hunting success of lions in Queen

533 Elizabeth National Park, Uganda. - Afr. J. Ecol. 22: 79-99. doi:10.1111/j.1365-

$534 \quad$ 2028.1984.tb00682.x 
535 Wardle DA, Bardgett RD, Klironomos JN, Setälä H, Van Der Putten WH, Wall DH

536 (2004) Ecological linkages between aboveground and belowground biota.

537 Science, 304(5677), 1629-1633. doi: 10.1126/science.1094875

538 Wilmers CC, Isbell LA, Suraci JP, Williams TM (2017) Energetics-informed behavioral

539 states reveal the drive to kill in African leopards. - Ecosphere 8: e01850. doi:

$540 \quad 10.1002 /$ ecs 2.1850

541 Werner EE, Peacor SD (2003) A review of trait-mediated indirect interactions in

542 ecological communities. - Ecology 84: 1083-1100. doi: 10.1890/0012-

543 9658(2003)084[1083:AROTII]2.0.CO;2

544 Wickham H (2016). ggplot2: Elegant graphics for data analysis. Springer-Verlag New

$545 \quad$ York. ISBN 978-3-319-24277-4, https://ggplot2.tidyverse.org.

546 Wootton JT (1993) Indirect Effects and Habitat Use in an Intertidal Community:

547 Interaction Chains and Interaction Modifications. - Am. Nat. 141: 71-89. doi:

$548 \quad 10.1086 / 285461$

549 Wootton JT (1994) The Nature and Consequences of Indirect Effects in Ecological

550 Communities. - Annu. Rev. Ecol. Evol. Syst. 25: 443-466. doi:

$551 \quad 10.1146 /$ annurev.es.25.110194.002303

552 Wootton JT (2002) Indirect effects in complex ecosystems: recent progress and future

553 challenges. - J. Sea Res. 48: 157-172. doi: 10.1016/S1385-1101(02)00149-1 


\section{Tables}

Table 1: Estimated mean and confidence interval at $95 \%$ for each level of elephant impacts of (a) the visibility (m) and (b) the distance to a potential ambush site (DPAS) (m).

\begin{tabular}{lllll}
\hline a & \% of impacted trees & $2.5 \%$ & Mean & $97.5 \%$ \\
\hline 0 & 0 & 15.7 & 16.7 & 17.8 \\
1 & {$[1,25]$} & 17.5 & 20.5 & 24 \\
2 & {$[26,50]$} & 20 & 23.7 & 28 \\
3 & {$[51,75]$} & 20.6 & 24.8 & 29.9 \\
4 & {$[76,100]$} & 24 & 30.7 & 39.1 \\
\hline b & $\%$ impacted trees & $2.5 \%$ & Mean & $97.5 \%$ \\
\hline 0 & 0 & 2.1 & 2.4 & 2.7 \\
1 & {$[1,25]$} & 2.5 & 3.5 & 4.7 \\
2 & {$[26,50]$} & 3.5 & 4.8 & 6.5 \\
3 & {$[51,75]$} & 3.2 & 4.5 & 6.3 \\
4 & {$[76,100]$} & 3.5 & 5.4 & 8.1 \\
\hline
\end{tabular}


Table 2: Logistic models examining (1) the effect of visibility (Vis) and distance to a potential ambush site (DPAS) on lion kill site location and (2) the effect of the level of elephant impacts (Ele) on lion kill site location. a) Approach at the large scale, comparing the characteristics of kill sites to characteristics of all random sites in areas intensively used by lions. b) Approach at the microhabitat scale, comparing the characteristics of kill sites to characteristics of paired random site representing the direct surrounding available habitat $(<150 \mathrm{~m})$. Models are ranked according to their BIC or QIC. Model-averaged estimates for the variables \pm standard error are shown at the bottom of each table. Variables considered as important were those for which $\beta \pm 1.96^{*}$ SE did not include zero.

\section{a) Large scale - Kill sites VS All random sites}

(1) - Kill sites / Random sites $~ D P A S+$ Vis

\begin{tabular}{|c|c|c|c|c|c|c|c|}
\hline & Candidate models & & df & $\mathrm{BIC}$ & $\Delta i$ & $w_{i}$ & $\operatorname{bcc} w_{i}$ \\
\hline 1 & Null & & 1 & 702.2 & 0.00 & 0.453 & 0.453 \\
\hline 2 & DPAS & & 2 & 702.7 & 0.45 & 0.361 & 0.814 \\
\hline 3 & Vis + DPAS & & 3 & 704.3 & 2.06 & 0.162 & 0.976 \\
\hline 4 & Vis & & 2 & 708.1 & 5.89 & 0.024 & 1 \\
\hline Variable & Average $\beta$ & $\mathrm{SE}$ & & & & & \\
\hline Vis & 0.22 & 0.25 & & & & & \\
\hline DPAS & -0.06 & 0.13 & & & & & \\
\hline \multicolumn{8}{|c|}{ (2) - Kill sites / Random sites $\sim$ Ele } \\
\hline & Candidate models & & $\mathrm{df}$ & $\mathrm{BIC}$ & $\Delta i$ & $w_{i}$ & $\operatorname{bcc} w_{i}$ \\
\hline 1 & Ele & & 2 & 696.6 & 0 & 0.943 & 0.943 \\
\hline 2 & Null & & 1 & 702.2 & 5.62 & 0.057 & 1 \\
\hline
\end{tabular}




$\begin{array}{lll}\text { Variable } & \text { Average } \beta & \text { SE } \\ \text { Ele } & 0.25 & 0.09\end{array}$

b) Microhabitat scale - Kill site VS Paired random site

(1) - Kill site / Paired random site $\sim$ DPAS + Vis

\begin{tabular}{|c|c|c|c|c|c|c|}
\hline & Candidate models & & QIC & $\Delta i$ & $w_{i}$ & bec $w_{i}$ \\
\hline 1 & Vis + DPAS & & 310.5 & 0.00 & 0.436 & 0.436 \\
\hline 2 & DPAS & & 310.6 & 0.13 & 0.408 & 0.844 \\
\hline 3 & Vis & & 312.7 & 2.22 & 0.144 & 0.988 \\
\hline 4 & Null & & 317.6 & 7.1 & 0.013 & 1 \\
\hline Variable & Average $\beta$ & SE & & & & \\
\hline Vis & -0.33 & 0.27 & & & & \\
\hline DPAS & -0.44 & 0.19 & & & & \\
\hline
\end{tabular}

(2) - Kill site / Paired random site $\sim$ Ele

\begin{tabular}{|c|c|c|c|c|c|c|}
\hline & Candidate models & & QIC & $\Delta i$ & $w_{i}$ & $\mathrm{bcc} w_{i}$ \\
\hline 1 & Null & & 317.6 & 0 & 0.596 & 0.596 \\
\hline 2 & Ele & & 318.4 & 0.78 & 0.404 & 1 \\
\hline Variable & Average $\beta$ & SE & & & & \\
\hline Ele & 0.004 & 0.07 & & & & \\
\hline
\end{tabular}




\section{$1 \quad$ Figure legends}

2 Figure 1: Boxplot distribution of a) the visibility and b) the distance to a potential ambush

3 site (DPAS) according to the five classes of level of elephant impacts, i.e. of percentage

4 of trees impacted by elephants (broken, coppiced and/or uprooted): class 0: no impact;

5 class 1: [1-25\%]; class 2: [26\%-50\%]; class 3: [51\%-75\%]; and class 4 [76\%-100\%]. The

6 notch represents the $95 \%$ confidence interval of the median. Points represent raw data

7 using geom_jitter function from ggplot2 package (Wikcham 2016).

9 Figure 2: (a) Relationship between the level of elephant impacts and the strength of this

10 factor on lions' kill site location at the large scale. (b) Relationship between the log-

11 transformed DPAS (for DPAS ranging from 0 to $50 \mathrm{~m}$ ) and the strength of this factor on

12 lions' kill site location at the microhabitat scale. The selection strength is

$13 \exp (\beta 0+\beta 1 *$ level of elephant impacts $)$ at the large scale and exp $(\beta 0+\beta 1 * \log (\mathrm{DPAS}+1))$

14 at the microhabitat scale, where $\beta 0$ is the intercept estimate and $\beta 1$ is the estimated

15 coefficient for the level of elephant impacts at the large scale and for $\log (\mathrm{DPAS}+1)$ at the

16 microhabitat scale. Dotted lines represent the standard errors.

18 Figure 3: A) Representation of the expected pattern under our initial hypotheses and the

19 observed pattern. 1) Expected pattern - Under our initial hypotheses, we expected higher

20 visibilities and DPAS in habitats with higher levels of elephant impacts, as well as more

21 lion kill sites in habitats characterized by a lower visibility and a shorter DPAS, and thus

22 more kills in non-impacted habitats. 2) Observed pattern - An increased visibility and

23 DPAS were effectively observed with the increase of the level of elephant impacts but 
24 not as strongly as expected (see the shape of the green area). At the large scale, lion kills

25 were, unexpectedly, more in highly elephant-impacted habitats. At the microhabitat scale,

26 lion kill sites were more in habitat characterized by a shorter DPAS. B) Representation of

27 the different scenarios envisaged to explain the observed pattern. We played on the

28 combination of three variables: the probability of prey presence, the probability that a

29 hunt will occur (with lions hunting more in high prey abundance habitat and/or with lions

30 hunting more in closed habitats), and 3) the probability of a kill, i.e. of a successful hunt

31 (with lions having a higher success rate in closed habitat). Patterns 8, 14 and 16 appear to

32 be the most likely to explain the observed pattern. 


\section{Figures}

\section{Figure 1}
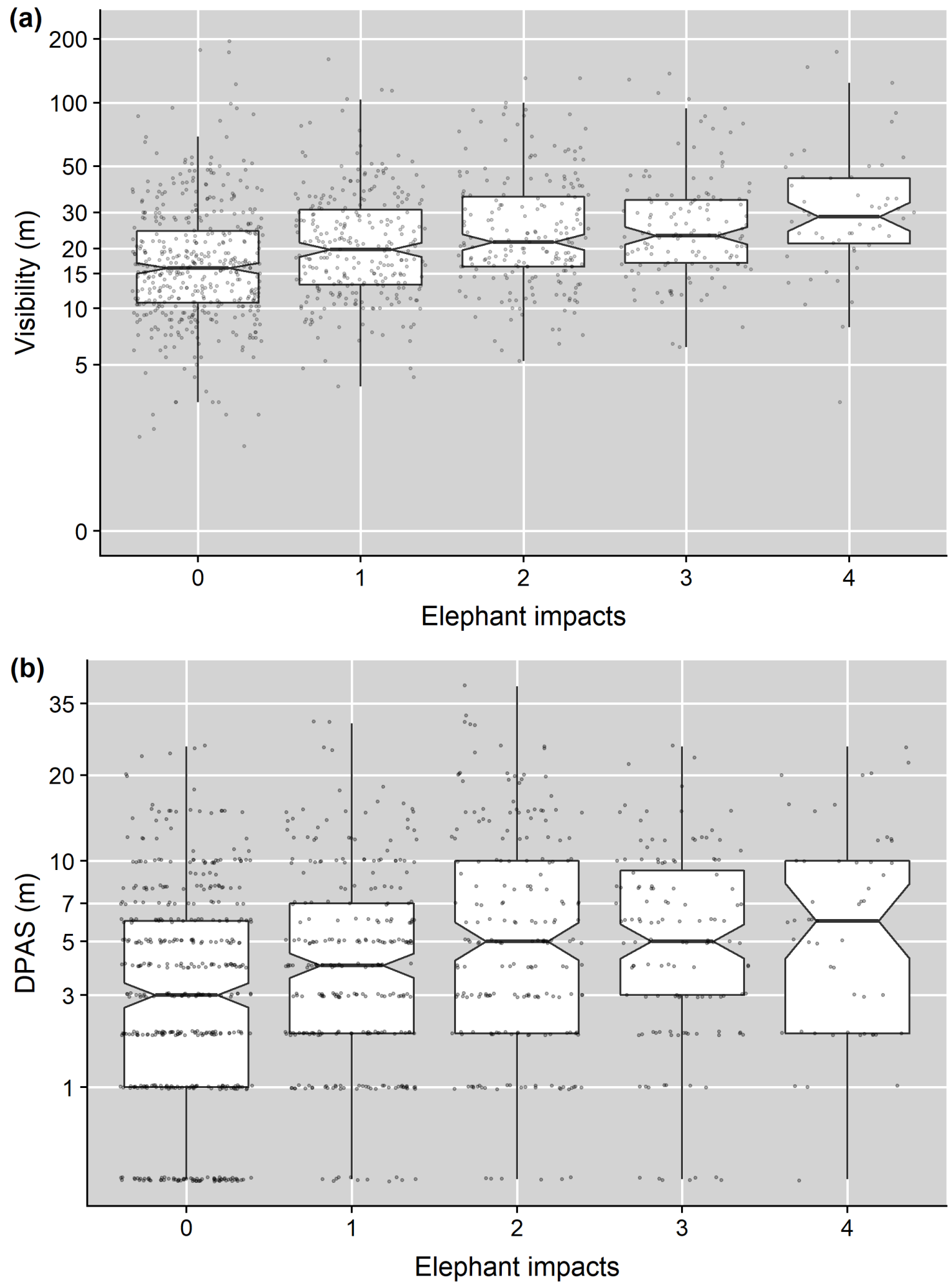


\section{Figure 2}
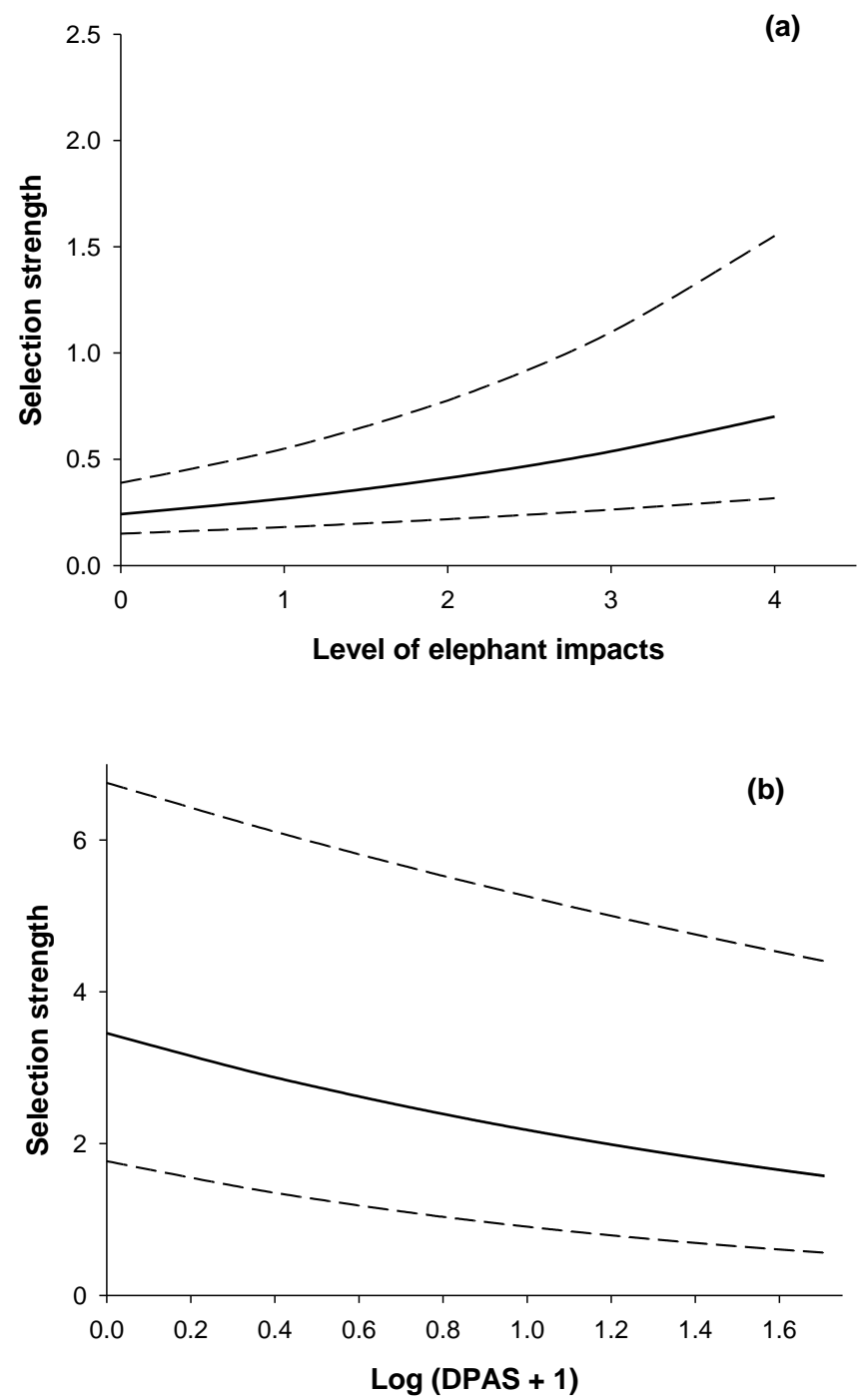
Figure 3 

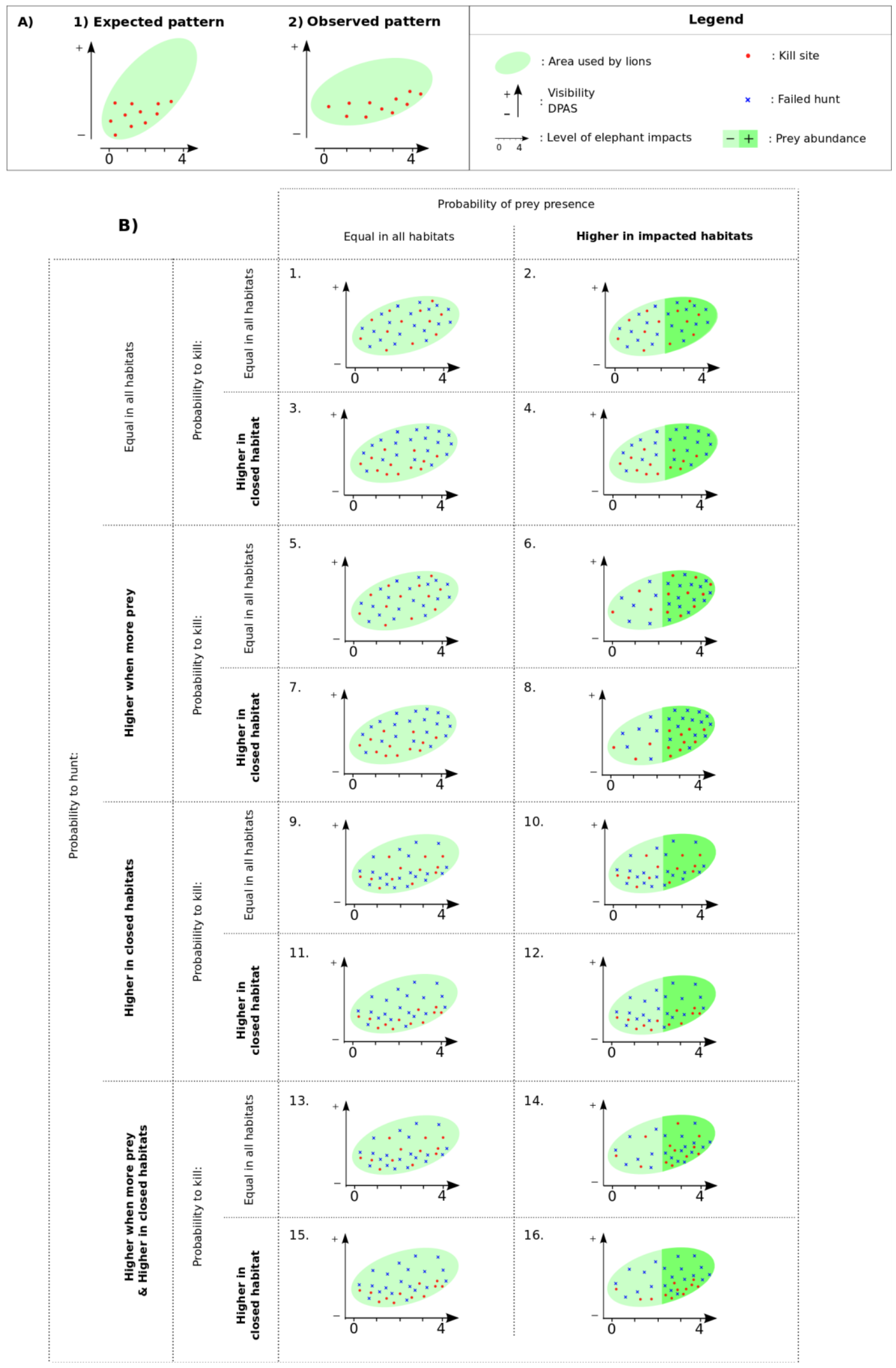